JOURNAL DE PHYSIQUE IV

Colloque C7, supplément au Journal de Physique III, Vol. 1, décembre 1991

\title{
LASER SPECTROFLUORIMETRIC DEVICE FOR CLINICAL IDENTIFICATION OF MALIGNANCIES AND THEIR MICROSCOPIC DLAGNOSIS
}

\author{
A.B. KARPOV, V.E. PROKOP'EV, V.V. UDUT, V.P. MODYAEV, S.A. NAUMOV, V.A CHICUROV, \\ V.I. ZAKHAROV and S.M. VOVK \\ Oncology Research Institute of Tomsk Scientific Centre, Academy of Medical Science, \\ Cooperativny Str. 5, Tomsk 634001, USSR \\ The Sorus Corporation, Sverdlovsk reg., Zarechny settl. 624051, USSR
}

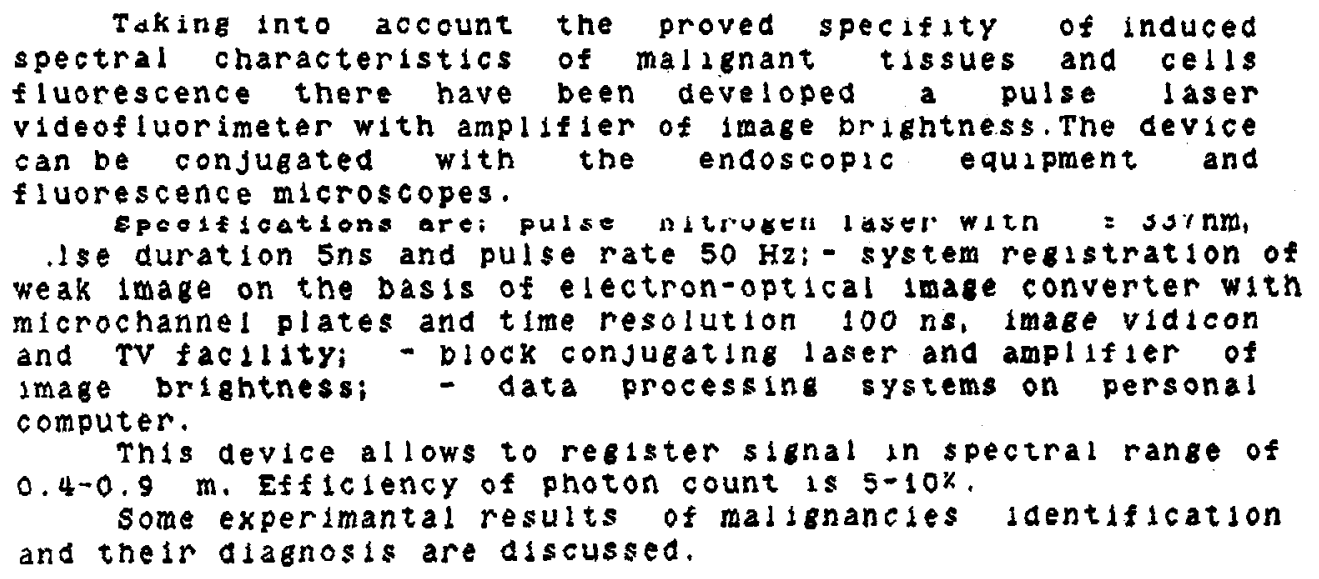

